\title{
Knowledge, attitude \& practice towards self-medication among nursing students in a teaching hospital of north India
}

\author{
Palvi Kudyar ${ }^{1, *}$, Shivani Rani², Pavan Malhotra ${ }^{3}$ \\ ${ }^{1,2}$ Senior Resident, ${ }^{3}$ Professor and Head, Dept. of Pharmacology, Acharya Shri Chander College of Medical Sciences, Jammu, India
}

*Corresponding Author: Palvi Kudyar

Email: pals2511@gmail.com

\begin{abstract}
Introduction: Self-medication the use of medication by a patient on his own initiative is increasing widely due to easy accessibility and availability of vast knowledge as a source of information about various drugs more so in the youth. This practice is larger in healthcare students and if used irrationally can lead to various adversities including resistance for drugs.

Objective: Aim of the study is to assess the prevalence, knowledge, attitudes \& practices towards self medication among nursing students in Acharya shri Chander College of medical sciences, Jammu.

Materials and Methods: A cross sectional study was conducted among first year, second \& third year nursing students using a 16 questions questionnaire comprising of knowledge, attitude \& practice related queries. The responses were recorded and assessment was made based on them.

Results: The prevalence of self-medication was high in the study population, with most people relying on previous prescriptions as drug source, using self medications for quick relief with risk of ADR being the most common cause of avoidance. Antipyretics were most rampantly used as self medication but there is lack of sufficient knowledge about the same. Though, the responders exhibit positive attitude and yearn to bring about change in the scenario with alteration of certain policies \& regulations.

Conclusion: There is a rise in the practice of self-medication among nursing students with lack of knowledge but positive attitude towards the same.
\end{abstract}

Keywords: Knowledge, Attitude, Practice, Self-medication, Nursing students.

\section{Introduction}

According to William Osler, a great feature which distinguishes man from animals is the desires to take medicine. ${ }^{1}$ Since time immemorial, people desire on local practitioners, traditional physicians or dais to acquire medicines, but with the advanced technology, vast knowledge being freely available \& easy accessibility, there is a growing concept of self-medication.

WHO defines self medication as the use of medication by a patient on his own initiative or on the advice of a pharmacist or a lay person instead of consulting a medical practitioner. ${ }^{2}$ It involves acquiring medicines without a prescription, resubmitting old prescriptions to purchase medicines, sharing medicines with relatives or members of one's own social circle or using leftover medicines stored at home. ${ }^{3}$ Medicines available for self-medication are often called nonprescription or over the counter drugs (OTC) which are available without prescription in pharmacies. Self-medication with OTC drugs following knowledge regarding the indication of drug, dosage, adverse effect, interactions, precautions, duration of use \& when to seek professional advice is termed as responsible self-medication.

In developing countries like India, not only OTC drugs, even prescription only drugs are easily accessible without prescription in pharmacy outlets. ${ }^{4}$ These practices make irrational use of medicines which promotes unwanted effects such as adverse drug reactions, resistance to pathogens, drug interactions, wastage of resources, delay in seeking professional advice and increased morbidity. ${ }^{5}$ Under dosage of self medicated drugs may not treat the symptoms completely \& over dosage may cause collateral damage to other organs.
Many studies have established that the practice of selfmedication is rampant among the nursing students. ${ }^{6,7}$ This may be due to their curriculum that makes them acquire basic knowledge regarding medicines, which may drive towards higher self-medication practices. Also, the youth are vastly influenced by the technology and can get information about most drugs from pompous advertisements as well as have access to them through websites, resulting in the hazards of irrational self-medication practices. ${ }^{8}$

Though, a number ofstudies have been undertaken to establish the prevalence of self-medication among nursing students, but majority of them were conducted in countries other than India. Hence, the pattern of this practice in our country largely remains uncharted \& unaccounted for. With this objective, the present cross-sectional study was done to ascertain the pattern, prevalence \& knowledge, attitude, practices towards self-medication practices among nursing students of our institute. The outcomes of the study can be used to promote health and to reduce drug related problems among nursing students.

\section{Materials and Methods}

A cross-sectional study to evaluate the knowledge, attitude\& practices among nursing students towards selfmedication was conducted in the department of Pharmacology, Acharya Shri Chander College of Medical Sciences, Jammu after obtaining due approval from the Institutional Ethics Committee.

The study participants included all first year, second year \& third year nursing students attending classes in the institute. Students of all ages \& both sexes were included in the study. Those students who did not volunteer to 
participate were excluded from the study. A questionnaire consisting of 16 questions was allotted to the students after giving a brief description of the nature of the study\& the procedure of completing the questionnaire was explained to them.

It was a self-administered questionnaire about responsible self-medication comprising of four parts to gather data regarding sociodemographic characteristics of the study population, knowledge, attitude and practices towards self-medication. The sociodemographic details included age, gender, residence and type of accommodation in the institute. The students were asked if they had taken self-medication in the past one year to compute the prevalence.

Knowledge towards self-medication was assessed through 7 multiple choice, closed and open ended questions. The number of students in favor of each answer was calculated and their frequency was calculated as percentage (\%) values.

Attitudes of the students towards self-medication were reflected through 3 statements made on the Likert's scale. The answers ranged from positive to negative responses as strongly agree 5, agree 4, neither agree nor disagree 2, strongly disagree 1 . The maximum score expected from all statements was 15 and minimum was 3 . If the students scored above or equal to 7 , will be considered positive attitude and $<7$ considered as negative attitude towards selfmedication practice. ${ }^{9}$

Practice towards self-medication was assessed through 5 multiple choice, closed and open ended questions. The number of students in favor of each answer was calculated and their frequency was calculated as percentage (\%) values.

The survey was descriptive and the data was summarised as counts and percentages. Microsoft Word \& Microsoft Excel programs were used to tabulate and analyze the data.

\section{Results}

A total of 100 first year, second year \& third year nursing students participated in the study and completed the questionnaire. Of these, 49 were males and 51 were female students. More number of students was less than 20 years old, with the average age being $20.2 \pm 1.8$ years. $63 \%$ of the respondents belonged to rural areas, whereas the rest $37 \%$ belonged to urban areas. (Table 1)
Table 1: Socio demographic pattern of respondents. $(\mathbf{n}=\mathbf{1 0 0})$

\begin{tabular}{|l|c|c|}
\hline Variable & Category & Frequency (\%) \\
\hline \multirow{3}{*}{ Age (years) } & Mean \pm S.D & $20.2 \pm 1.8$ \\
\cline { 2 - 3 } & $<20$ years & 53 \\
\cline { 2 - 3 } & >20 years & 47 \\
\hline \multirow{2}{*}{ Gender } & Males & 49 \\
\cline { 2 - 3 } & Females & 51 \\
\hline Residence & Rural & 63 \\
\cline { 2 - 3 } & Urban & 37 \\
\hline Accommodation & Day scholar & 81 \\
\cline { 2 - 3 } & Hostelites & 19 \\
\hline
\end{tabular}

On computing the questionnaire, it was seen that $76 \%$ of the nursing students had taken self-medication in the past one year while $24 \%$ responded in negative to this. (Fig. 1)

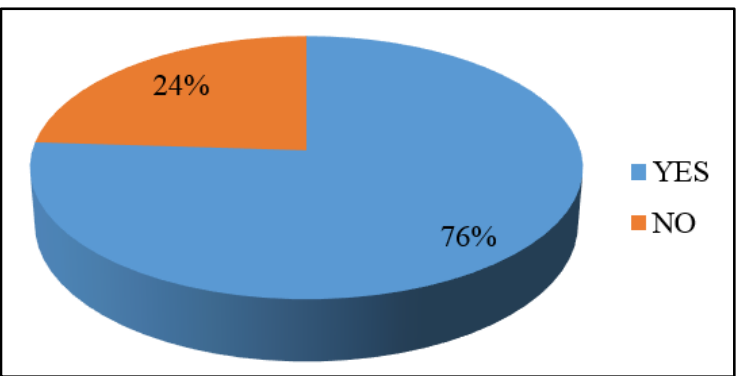

Fig. 1: Prevalence of self-medication among nursing students $(\mathbf{n}=\mathbf{1 0 0})$

On evaluating the responses to the knowledge assessment, it was noted that $65 \%$ students could correctly define self-medication while $27 \%$ were not sure about the definition. $69 \%$ of the answers pointed towards previous prescription being the major source of information about drugs for self medication, followed by the information from pharmacist $(48 \%)$ and $37 \%$ from advertisements or the internet. Majority stated the reason for self medication that it provides quick relief (44\%), 32\% find it a way to avoid going to the doctor. When questioned on the reasons to not take self medication, the students list risk of adverse effects $(54 \%)$ as the major cause followed by risk of misdiagnosing $(50 \%)$.

Antipyretics $(68 \%)$ were the most commonly used drugs for self medication, followed by the analgesics $(65 \%)$ and the antibiotics $(46 \%)$ in the nursing student's population. (Table 2)

Table 2: Knowledge towards self- medication among nursing students $(\mathbf{n}=100)$

\begin{tabular}{|c|c|c|}
\hline Variable & Category & Frequency (\%) \\
\hline \multirow{4}{*}{ Define self-medication } & Yes & 65 \\
\hline \multirow{3}{*}{$\begin{array}{l}\text { Source of information about drugs for } \\
\text { self medication** }\end{array}$} & No & 8 \\
\cline { 2 - 3 } & Not sure & 27 \\
\cline { 2 - 3 } & Textbooks/Classes & 11 \\
\cline { 2 - 3 } & Advertisements/Internet & 37 \\
\cline { 2 - 3 } & Pharmacist & 48 \\
\hline Reasons in favor of self-medication** & Previous prescriptions & 69 \\
\hline
\end{tabular}




\begin{tabular}{|c|c|c|}
\hline & Quick relief & 44 \\
\hline & Time saving & 28 \\
\hline & Confidence on knowledge & 4 \\
\hline \multirow{6}{*}{$\begin{array}{l}\text { Reasons for not taking } \\
\text { Self-medication** }\end{array}$} & Economical & 2 \\
\hline & Ease \& Convenience & 21 \\
\hline & Crowd Avoidance & 7 \\
\hline & Any other & 1 \\
\hline & Lack of knowledge & 33 \\
\hline & Risk of wrong drugs & 29 \\
\hline & Risk of misdiagnosing & 50 \\
\hline & Risk of drug dependence & 23 \\
\hline & Risk of adverse effects & 54 \\
\hline & Any other & 2 \\
\hline \multirow{2}{*}{$\begin{array}{l}\text { Aware about reason to } \\
\text { continue/discontinue }\end{array}$} & Yes & 68 \\
\hline & No & 32 \\
\hline \multirow[t]{3}{*}{ Drugs taken for self medication** } & Antibiotics & 46 \\
\hline & Antiemetics & 19 \\
\hline & Antipyretics & 68 \\
\hline & Analgesics & 65 \\
\hline & Antihistaminics & 24 \\
\hline & Vitamins & 31 \\
\hline & Antidiarrheal & 22 \\
\hline & Antispasmodics & 7 \\
\hline & Sedatives & 6 \\
\hline & Antitussives & 44 \\
\hline & Others & 2 \\
\hline \multirow[t]{3}{*}{ Sources of drugs used $* *$} & Medical store & 46 \\
\hline & Home & 58 \\
\hline & Parents & 12 \\
\hline
\end{tabular}

$(* *$ - more than one response)

Among all the 100 respondents, for elucidating the attitude patterns, most gave "strongly agree" and "agree"

about various statements of self-medication. The answers point towards positive attitude of most students (92\%) (Fig. $2,3)$.

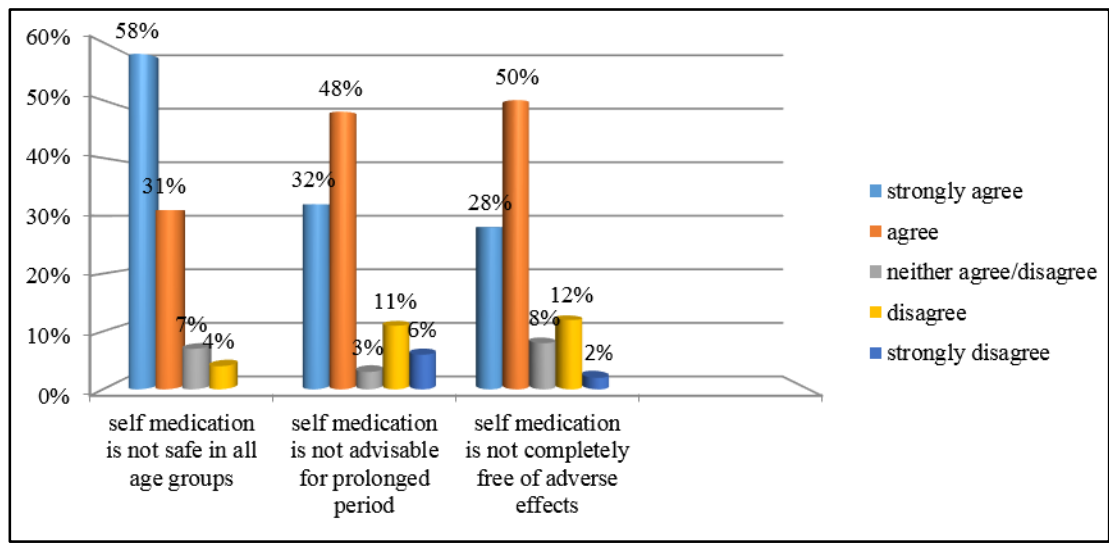

Fig. 2: Attitude towards self-medication among nursing students $(n=100)$ 


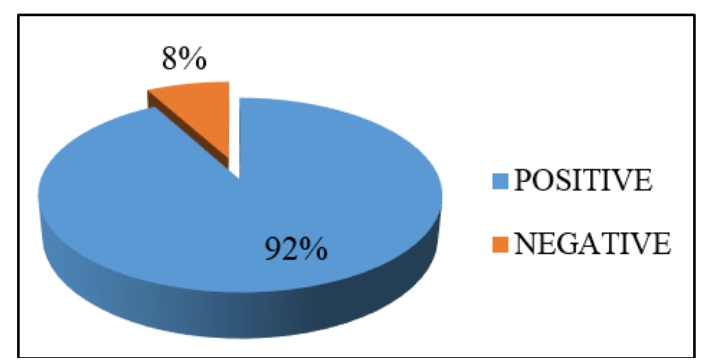

Fig. 3: Overall attitude towards self-medication among nursing students $(\mathbf{n}=\mathbf{1 0 0})$
Under the practice questionnaire, $66 \%$ students sometimes visited a qualified medical officer, while $81 \%$ took medication without reading the leaflet/package insert.

To address this advancing problem majority (42\%) suggest that the sale of medicines should be stopped without prescription and the other 29\% advocate the raising awareness \& education. (Table 3 )

Table 3: Practice towards self- medication among nursing students $(n=100)$

\begin{tabular}{|l|c|c|}
\hline Variable & Category & Frequency (\%) \\
\hline \multirow{3}{*}{ Whether visited qualified medical off } & Always & 28 \\
\cline { 2 - 3 } & Sometimes & 66 \\
\cline { 2 - 3 } & Rarely & 6 \\
\hline \multirow{2}{*}{$\begin{array}{l}\text { Do you take self-medication without reading } \\
\text { leaflet/package insert }\end{array}$} & Yes & 19 \\
\hline \multirow{2}{*}{ Have you given prescription to someone else } & No & 81 \\
\cline { 2 - 3 } & Yes & 69 \\
\hline \multirow{2}{*}{$\begin{array}{l}\text { Do you take self-medication for long period } \\
\text { without advice }\end{array}$} & No & 15 \\
\hline \multirow{2}{*}{\begin{tabular}{l} 
How can you prevent self medication** \\
\cline { 2 - 3 }
\end{tabular}} & Yes & 85 \\
\cline { 2 - 3 } & No & 42 \\
\cline { 2 - 3 } & Prevent supply of drugs without \\
\cline { 2 - 3 } & prescript & 29 \\
\cline { 2 - 3 } & Strict rules enforced & 7 \\
\cline { 2 - 3 } & Making health services strong & 6 \\
\hline
\end{tabular}

(**- more than one response)

\section{Discussion}

The International Pharmaceutical Federation defines self-medication as the use of non-prescription medicines by people on their own initiative. ${ }^{10}$ Self-care including selfmedication has been a feature of healthcare for many years with people nowadays, being keen to accept more personal responsibity for their health status. Self medication has both pros \& cons but, if used irrationally may lead to adverse outcomes for the patient. This is known to be a widely prevailing problem among health-care students. ${ }^{11}$ Hence, this KAP study was done to evaluate the practices, attitude and perceptions of self-medication among nursing students.

The prevalence of self-medication among the nursing students of our institute was as high as $76 \%$, this is supported by various studies done in our country. ${ }^{12,13}$ Also, the prevalence was observed to be higher among females in our study. Similar observations were made in studies done in India and outside as well. ${ }^{14,15}$ This may be due to more reliance of females on alternate treatments than to get proper line of treatment.

$65 \%$ of the students could define Self medication, which was also the case in the study done by James et al. ${ }^{16}$ Kayalvizhi et al in their study established that previous prescriptions were the most important source of information of drugs for self medication which was in concurrence with our study. ${ }^{12}$ On the contrary, some studies state textbooks as the primary source of information, which was in opposition to our study. ${ }^{17,18}$

In agreement with Bollu et al, our study also states that quick relief is the most important reason for self-medication followed by no need to visit the doctor. ${ }^{19}$ This may be due to nursing students having basic knowledge about drugs, hence, lesser predisposition to seek physician's advice. Risk of adverse reactions was the most common reason to avoid self medication which was mirrored in other studies as well. ${ }^{20}$ In similar results, Kumar $\mathrm{N}$ also states antipyretics as the most common class of drugs used by participants of the study ${ }^{21}$ followed by analgesics and antibiotics. Antibiotics use is shown to be higher for self medication in developing countries. $^{22,23}$

The study shows positive attitude of the nursing students towards self-medication as is mirrored by Susheela $\mathrm{F}$ et al. $^{24}$ which can be made an evidence to conduct educational training programs for responsible self medication for general public \& nursing students. Despite the positive attitude, there is less knowledge about the selfmedication practices and there is need for change in certain policies and regulations, preventing the supply of drugs without prescriptions being the foremost according to our study, being supported by other studies too. ${ }^{21}$ 


\section{Conclusion}

Hence, Self-medication is very common among nursing students with high prevalence, facilitated by easy availability of information on drugs and easy accessibility to acquire medicines. There is lack of sufficient knowledge about responsible self-medication, though with the existent positive attitude of the responders, changes can be brought upon in this scenario. The use of seminars, workshops can be made to disseminate information to the students, with application of strong policies to halt the growing trend.

This study was limited to single setting, more multicentric studies need to be carried out among nursing students and general population at large to understand various factors influencing self-medicine in India. The role of socio-economic status \& its influence on self medication need to be explored in future studies.

\section{Conflict of Interest: None.}

\section{References}

1. Balamurugan E, Ganesh K. Prevalence and pattern of selfmedication use in coastal regions of South India. BJMP. 2011;4(3):428.

2. Porteous T, Bond C, Hannaford P, Sinclair H. How and why are non-prescription analgesics used in Scotland. Fam Pract. 2005;22(1):78-85.

3. Loyola Al, Lima-Costa MF, Uthoa E. Bambui Project: a qualitative approach to self-medication. Cad Saude Publica. 2004;20(6):1661-1669.

4. Pereira FS, Bucaretchi F, Stephan C, Cordeiro R. Selfmedication in children and adolescents. $J$ Pediatr (Rio J) 2007;83:453-458

5. Hansen EH, Holstein BE, Due P, Currie CE. International survey of self-reported medicine use among adolescents. Ann Pharmacother. 2003;37:361-366.

6. Ali AS, Ahmed J, Sonekhi GB, Fayyaz N, Zainulabdin Z, Jindani J, et al. Practices of self-medication with antibiotics among nursing students of institute of nursing, Dow University of Health Sciences, Karachi, Pakistan. J Pak Med Assoc. 2016;66:235-237.

7. Celik S, Alacadag M, Erduran Y, Erduran F, Berberkayar N. The investigation of antibiotic use situations, health school students. J Hum Sci (Turkish). 2010;7:1125-1135.

8. Venkataraman G, Gangadharappa SK, Jacob J, Bhaskar N, Kulkarni SB, Gupta A. Assessment of self-medication practice among students of a dental college in Bangalore city: a crosssectional study. J Indian Assoc Public Health Dent. 2017; 15:73-77.

9. Levya M, Byrd T, Tarwater P. Attitude towards cervical cancer screening: a study of beliefs among women in Mexico. Calif $J$ Health Promot. 2006;4:13-24.

10. Joint Statement by the International Pharmaceutical Federation and The World Self-medication Industry. (cited: September 2018) Available from: http://www.fip.org/uploads/www/database_file.php?id=241\&t able_id

11. Gupta S, Singh M. Self-medication among North Indian first year undergraduate healthcare students: a questionnaire based study. Trop J Med Res. 2016;19:162-167.

12. Kayalvizhi S, Senapathi R .Evaluation of the perception, attitude and practice of self-medication among business students in 3 select cities, South India. IJEIMS. 2010;(3):40 44.

13. Verma RK, Mohan L, Pandey M .Evaluation of self medication among professional students in North India: proper statutory drug control must be implemented. Asian J

Pharmaceutical Clin Res. 2010;3(1):60-64.

14. Banerjee I, Bhadury T. Self-medication practice among undergraduate medical students in a tertiary care medical college. West Bengal J Postgrad Med. 2012;58:(2):127-131.

15. Smogavec M, Softič N, Kersnik J, Klemenc-Ketiš Z. An overview of self-treatment and self medication practices among Slovenian citizens. Slovenian Med J. 2010;79:757-763.

16. James H, Handu SS, Al Khaja KA, Otoom S, Sequeira RP. Evaluation of the knowledge, attitude and practice of selfmedication among first-year medical students. Med Princ Pract. 2006;15(4):270-275.

17. Badiger S, Kundapur R, Jain A, Kumar A, Pattanshetty S, et al. Self-medication patterns among medical students in South India. Australas Med J. 2012;5(4):217-220.

18. Abay SM, Amelo W. Assessment of self-medication practices among medical, pharmacy, and health science students in Gondar University, Ethiopia. J Young Pharm. 20102(3):306310.

19. Bollu M, Vasanthi B, Chowdhary PS, Chaitanya DS, Nirojini PS, Nadendla RR. Prevalence of self medication among pharmacy students of Guntur: a questionnaire based study. World J Pharm Sci. 2014;3:810-826.

20. Mehta R, Sharma S. Knowledge, Attitude \& Practice of self medication among medical students. IOSR-JNHS 2015;4(1):89-96

21. Kumar N, Kanchan T, Unnikrishnan B. Perceptions and practices of self-medication among medical students in coastal South India. PLoS One. 2013;8(8):e72247.

22. El Ezz NF, Ez-Elarab HS .Knowledge, attitude and practice of medical students towards self-medication at Ain Shams University. Egypt J Prev Med Hyg. 2011;52(4):196-200.

23. Fadare JO, Tamuno I. Antibiotic self-medication among university medical undergraduates in Northern Nigeria. $J$ Public Health Epidemiol. 2011; 3(5):217-220.

24. Susheela F, Goruntla N, Bhupalam PK, Veerabhadrappa KV, Sahithi B, Ishrar SMG. Assessment of knowledge, attitude, and practice toward responsible self-medication among students of pharmacy colleges located in Anantapur district, Andhra Pradesh, India. J Educ Health Promot. 2018;7:96.

How to cite this article: Kudyar P, Rani S, Malhotra P. Knowledge, attitude \& practice towards self-medication among nursing students in a teaching hospital of north India. Indian J Pharm Pharmacol. 2018;5(4):159-163. 